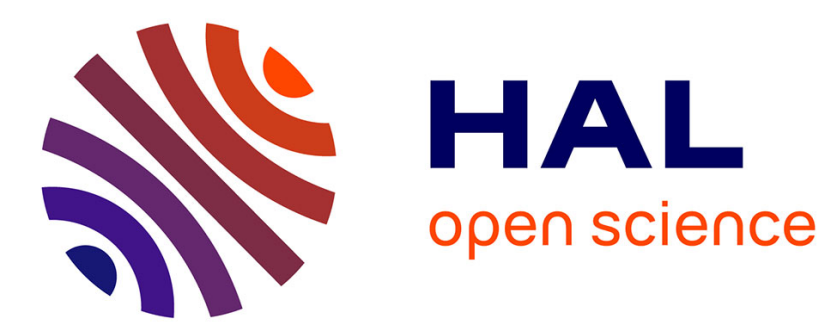

\title{
Some Armature Reaction Compensation Methods. Numerical Design of Experiments and Optimisation For a Hybrid Excitation Machine
}

Li Li, Albert Foggia, Afef Kedous-Lebouc, Jean-Claude Mipo, Luc Kobylanski

\section{- To cite this version:}

Li Li, Albert Foggia, Afef Kedous-Lebouc, Jean-Claude Mipo, Luc Kobylanski. Some Armature Reaction Compensation Methods. Numerical Design of Experiments and Optimisation For a Hybrid Excitation Machine. IEMDC, 2009, Miami, United States. hal-00394663

\section{HAL Id: hal-00394663 \\ https://hal.science/hal-00394663}

Submitted on 12 Jun 2009

HAL is a multi-disciplinary open access archive for the deposit and dissemination of scientific research documents, whether they are published or not. The documents may come from teaching and research institutions in France or abroad, or from public or private research centers.
L'archive ouverte pluridisciplinaire HAL, est destinée au dépôt et à la diffusion de documents scientifiques de niveau recherche, publiés ou non, émanant des établissements d'enseignement et de recherche français ou étrangers, des laboratoires publics ou privés. 


\title{
Some Armature Reaction Compensation Methods Numerical Design of Experiments and Optimization For A Hybrid Excitation Machine
}

\author{
$\mathrm{Li} \mathrm{Li}^{*}$, Albert Foggia*, Afef Kedous-Lebouc*, Jean-Claude Mipo ${ }^{* *}$ and Luc Kobylansky** \\ ${ }^{*}$ G2Elab, Grenoble Electrical Engineering Laboratory \\ Grenoble INP-UJF-CNRS UMR 5269 \\ 961, Rue de la Houille Blanche \\ ENSIEG-BP 46-F38402 Saint-Martin-d'Hres Cedex,France \\ Telephone: 0033(0)1.48.98.86.67 \\ Email: li.li@g2elab.grenoble-inp.fr \\ **Valeo Equipements Electriques Moteur \\ 2, Rue André Boulle, F94046 Créteil Cedex, France
}

\begin{abstract}
This paper presents a hybrid excitation synchronous machine which combines a permanent magnet excitation with a wound field one. With two sources of flux, this kind of machines is cited more and more frequently in vehicle application for easier control of flux. After a brief description of the structure, some methods will be presented to improve the performances of this machine. Simulation results have shown that the armature reaction has a magnetizing effect when it enters in a pole face and a demagnetizing effect when getting out from the same pole, which distorts the main field and to some extent deteriorates the performances of the machines. The methods we present here are based on the principle of armature reaction compensation which might be extended to many synchronous machines. And then, in the last section, a general optimization tool (numerical design of experiments and optimization) is used to maximize the impacts of these methods.
\end{abstract}

\section{INTRODUCTION}

Synchronous machines have many interesting properties which may be used in the hybrid vehicule applications.[1]-[2] The ability these machines present for controlling the rotor magnetic flux is a good advantage for speed control. This paper presents the machine which we investigated and some improvements of the electromechanical characteristics of the machine. In the sizing phase, we have investigated the flux path of the armature reaction which sweeps the pole surface in such a way that it reinforces the main field on one side of the pole and weakens on the other side. We have been inspired by the compensating windings in the DC machines and introduced these ideas in our machine. Based on the same principle, the armature reaction compensation, a progressive air gap and the slits in the poles present also some promising results.

\section{MACHINE DESIGN}

The machine presented herein is a motor /generator for hybrid vehicle application. Its original structure is a wound rotor with interpolar magnets (Fig.1). The windings are supplied in such a way that the resulting flux opposes the flux of the
TABLE I

PRINCIPLE CHARACTERISTICS

\begin{tabular}{|c||c|}
\hline Description & Value \\
\hline \hline Pole pairs & 6 \\
\hline Slot number & 54 \\
\hline Fractional pitch & $8 / 9$ \\
\hline Active length $(\mathrm{mm})$ & 240 \\
\hline Iron diameter $(\mathrm{mm})$ & 200 \\
\hline Base speed $(\mathrm{rpm})$ & 3000 \\
\hline Permanent power $(\mathrm{kW})$ & 40 \\
\hline
\end{tabular}

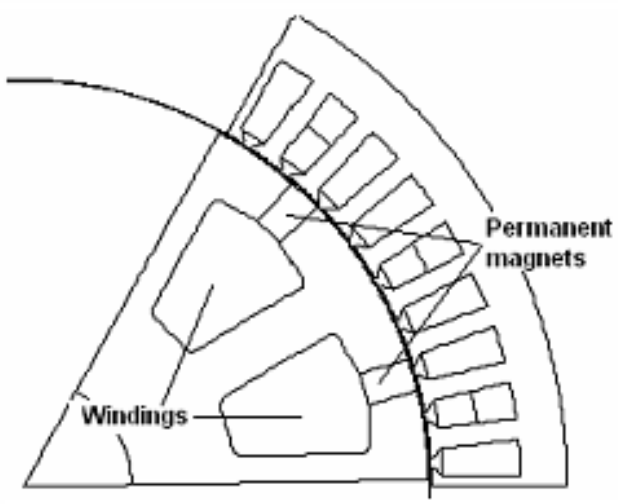

Fig. 1. Hybrid excitation machine

magnets in the interpolar regions. Thus, for flux weakening, it is efficient to reduce the excitation current. An optimum exists for the percentage of flux generated by the magnets and by the windings for the purpose of loss minimization. The main characteristics of this machine are presented in Tab.I.

A chorded winding is used in order to reduce the torque ripple and some harmonics. 


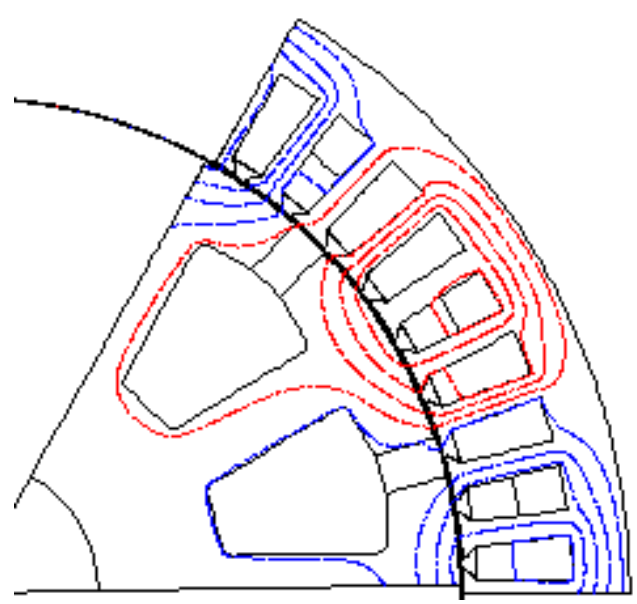

(a) Flux lines



(b) Radial flux density

Fig. 2. Armature magnetic reaction

\section{COMPENSATION FOR THE ARMATURE REACTION}

In synchronous machines, the torque is produced by the interaction between the main field and the armature field. The



Fig. 3. Flux density along the air gap @ 3000 rpm under load

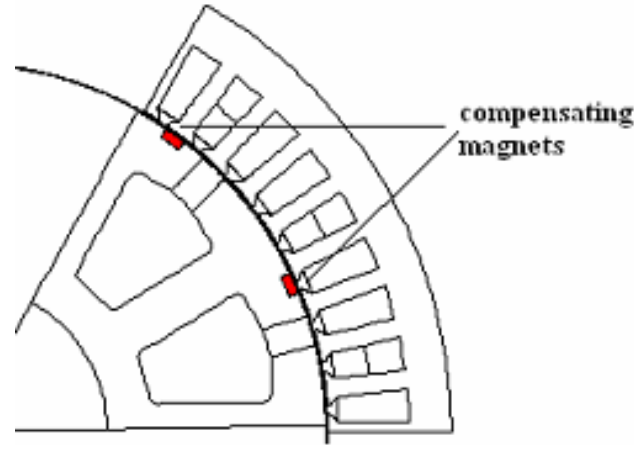

Fig. 4. Location of the compensating magnets

latter sweeps the pole faces in an almost constant way as presented in Fig.2.

As is shown in Fig.3, the flux density curve becomes asymmetrical along the air gap due to the armature reaction which has a magnetizing effect when it enters in a pole face and a demagnetizing effect when getting out from the same pole, which distorts the main field. The flux per pole remains unchanged if the machine does not saturate. But if saturation occurs, the net flux per pole will be reduced and the electromechanical characteristics will also be less important.[7]

In this section, we present three methods to reduce or eliminate this effect. [3]-[4].

\section{A. Compensating magnets}

Similarly to the electrical circuit used in the DC machines, we introduced in our application permanent magnets in the rotor. The magnets placed in the pole faces are conveniently oriented with respect to the orientation of the armature reaction (Fig.4).

Fig.5 and Fig.6 illustrate the compensation principle by showing separately the flux of compensating magnets and its superposition with the flux of stator currents.

Simulation results (Fig.7) show that the torque at the base speed has been increased by about $7 \%$. The flux density is improved around the demagnetizing side of the pole (Fig.8), which contributes to the increase of the fundamental (Fig.9) and also to the increase of the torque.

TABLE II

TORQUE FOR DIFFERENT ARMATURE CURRENT DENSITY

\begin{tabular}{|c|c|c|c|c|c|c|}
\hline$I_{s}\left(A / m m^{2}\right)$ & \multicolumn{2}{|r|}{5} & \multicolumn{2}{|r|}{10} & \multicolumn{2}{|c|}{15} \\
\hline & - & magnets & - & magnets & - & magnets \\
\hline$\Gamma(N . m)$ & 180 & 191 & 291 & 352 & 330 & 456 \\
\hline$H(k A / m)$ & - & 242 & - & 378 & - & 446 \\
\hline$I_{s}\left(A / m^{2}\right)$ & \multicolumn{2}{|r|}{20} & \multicolumn{2}{|c|}{25} & \multicolumn{2}{|c|}{30} \\
\hline & - & magnets & - & magnets & - & magnets \\
\hline$\Gamma(N . m)$ & 351 & 534 & 365 & 594 & 378 & 640 \\
\hline$H(k A / m)$ & - & 569 & - & 686 & - & 736 \\
\hline$I_{s}\left(A / m^{2}\right)$ & \multicolumn{2}{|r|}{35} & \multicolumn{2}{|c|}{40} & & \\
\hline & - & magnets & - & magnets & & \\
\hline$\Gamma(N . m)$ & 390 & 676 & 403 & 706 & & \\
\hline$H(k A / m)$ & - & 768 & - & 799 & & \\
\hline
\end{tabular}






(a) Flux lines

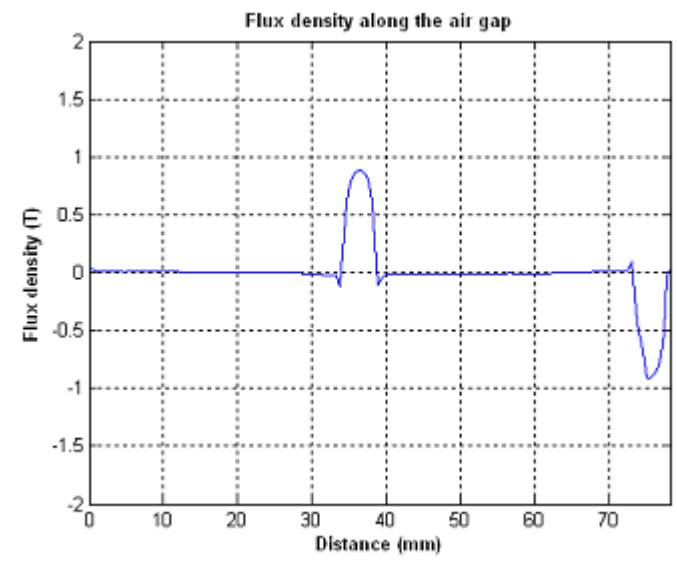

(b) Radial flux density

Fig. 5. Compensating magnets only

Besides, the compensating magnets present another interesting phenomenon when we increase the armature current density from $4 \mathrm{~A} / \mathrm{mm}^{2}$ to $40 \mathrm{~A} / \mathrm{mm}^{2}$ above which the demagnetization risk becomes serious. Simulation results have shown that the torque at the base speed has been practically doubled with the compensating magnets when armature current density reaches $40 \mathrm{~A} / \mathrm{mm}^{2}$.

The remarkable difference between the two curves shown in Fig.10 (Tab.II) can be explained by the fact that a higher current density causes more important armature reaction and local saturation in the machine, for that reason the impact of the compensating magnets becomes more important ex: at $40 \mathrm{~A} / \mathrm{mm}^{2}$.This fact is useful for the vehicle starting up because a very high torque is required for a short period of time.

This impact of the compensating magnets occurs in one rotation direction only. As in our application, the hybrid vehicles, one rotation direction plays the prominent part in the whole cycles.

The effect of the compensating magnets is positive in generator mode as well as in motor and stator mode. The

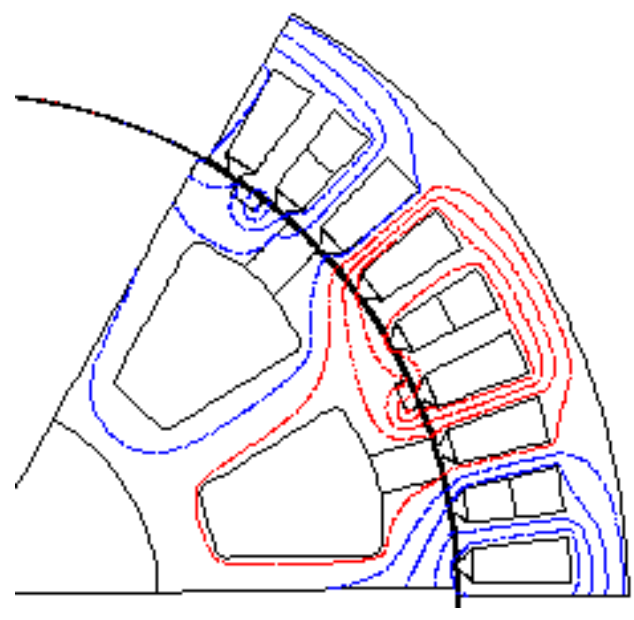

(a) Flux lines

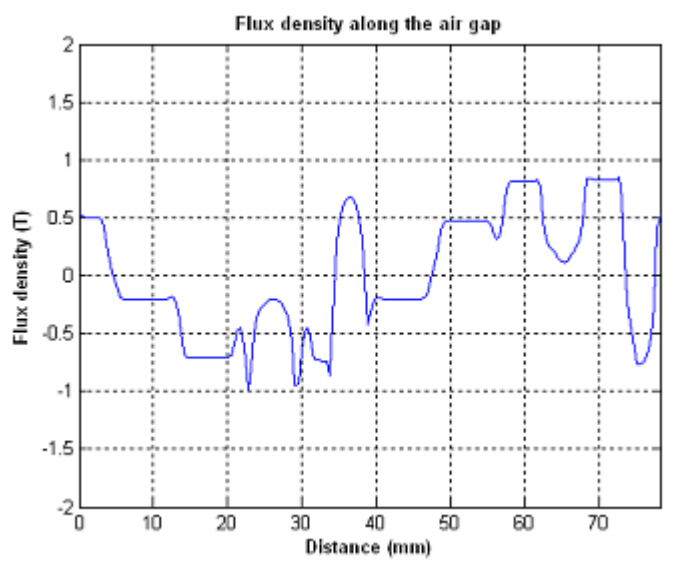

(b) Radial flux density

Fig. 6. Effect of the compensating magnets on the armature reaction

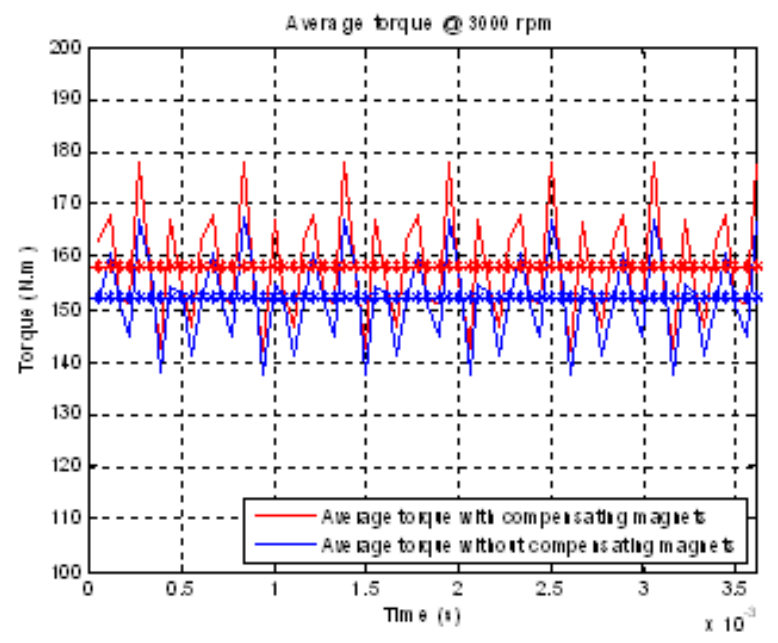

Fig. 7. Comparison of torque @3000rpm

output, the current through a full wave bridge rectifier of six diodes, has been increased by about $6 \%$ at $3000 \mathrm{rpm}$ (Fig.11) and $5 \%$ at $6000 \mathrm{rpm}$. As we can see in the Fig.12, the flux 


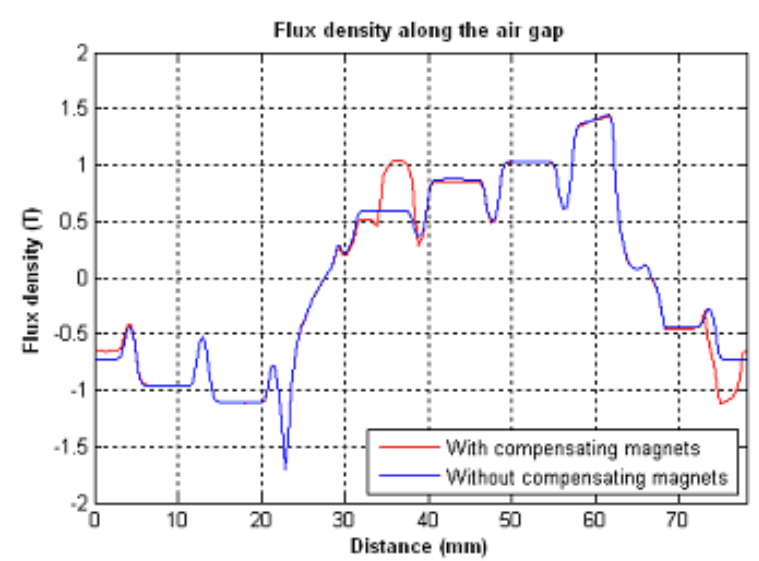

Fig. 8. Impact of the compensating magnets



Fig. 9. FFT of the flux density along the air gap @3000rpm under load

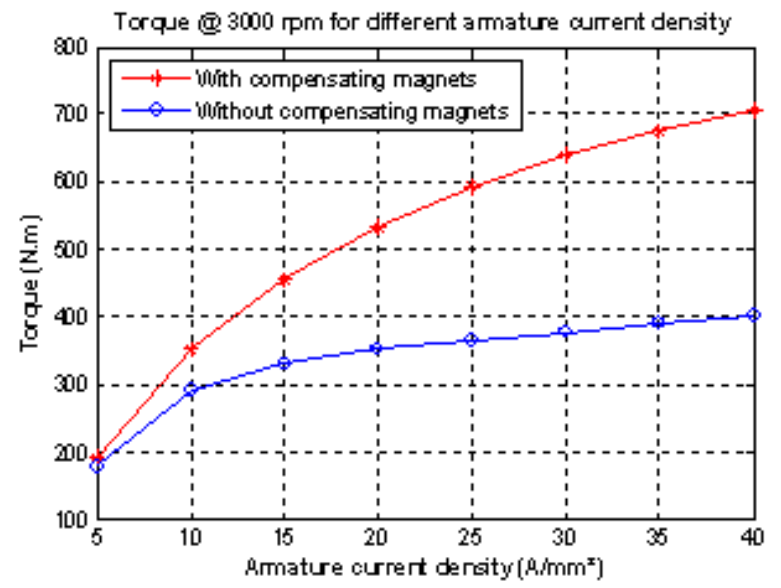

Fig. 10. Torque for different armature density

density has been increased locally by 0.14 Tesla which is not negligible for the machine performances.

The compensation impact has been tested for different load angles as in Fig.13. The intersection of the two curves can be explained by the fact that the compensating magnets are designed for a pre-selected load angle, ie the optimal angle in



Fig. 11. Output with/without compensating magnets @3000rpm

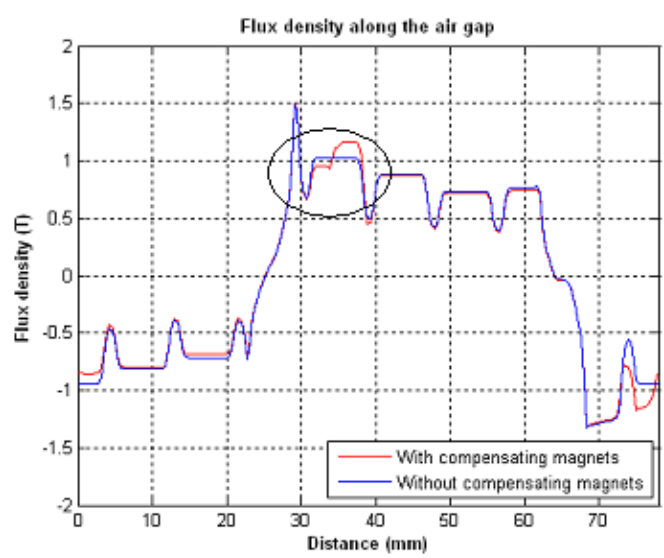

Fig. 12. Flux density along the air gap with/without compensating magnets

our case.

\section{B. Progressive air gap}

Because of the armature reaction, an asymmetry is created in the air gap because one side of the pole is more saturated



Fig. 13. Compensation impact for different load angles 


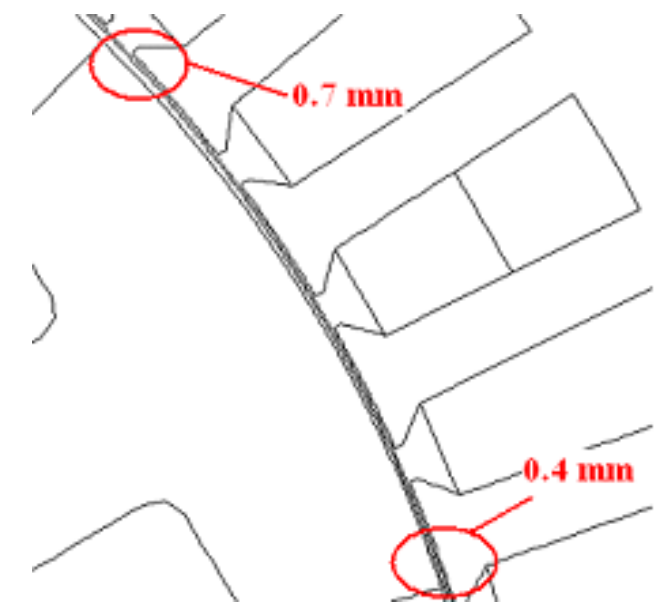

Fig. 14. Tangential air gap

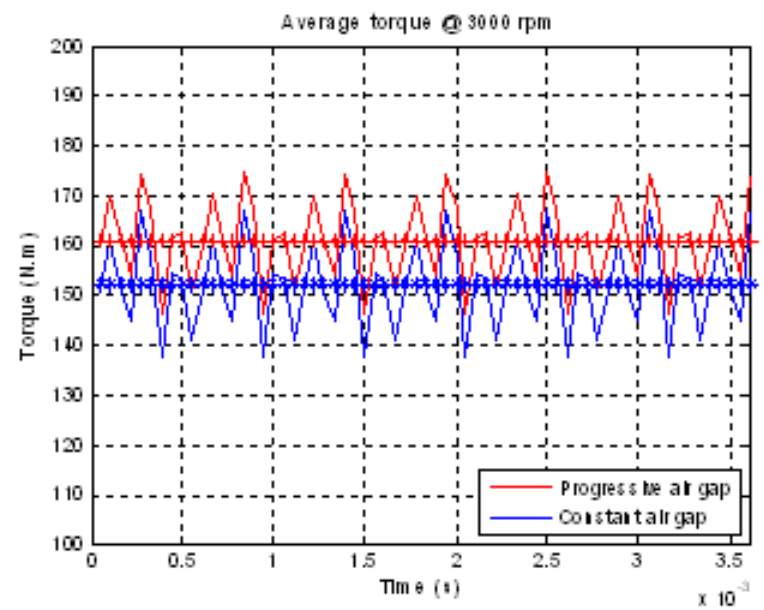

Fig. 15. Comparison of torque @3000rpm for progressive/constant air gap

than the other. In order to break this asymmetry, a variable air gap is adopted in which the air gap of the more saturated side is enlarged and the other one is reduced, meanwhile the average

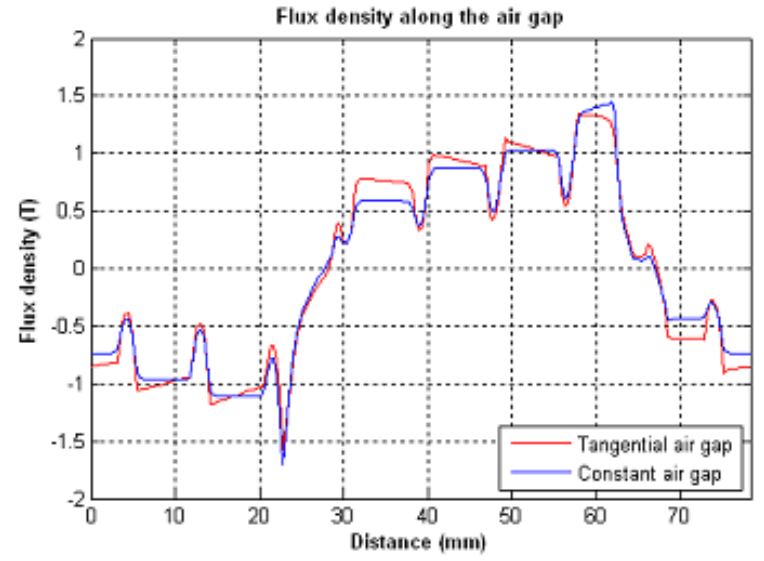

Fig. 16. Comparison of flux density for tangential/constant air gap

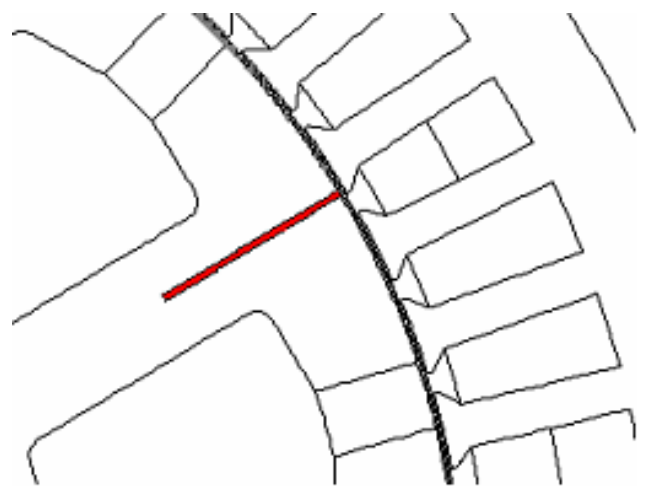

Fig. 17. Slit in the pole

air gap remains unchanged. In other words, the constant air gap of $0.6 \mathrm{~mm}$ is replaced by a tangential air gap, the wider side of which is $0.7 \mathrm{~mm}$ and the smaller side becomes $0.4 \mathrm{~mm}$ (Fig.14).

As is shown by Fig.16, the flux density is increased nearly all the way along the air gap except the most saturated point that we have seen previously, which makes the flux density in the air gap more homogenous. This reduction of armature reaction impact leads to a torque increase by $6 \%$ and a lower ripple rate (Fig.15).

\section{Slits and magnets in slits}

We have also tried to place slits with a width similar to the air gap and one-third of the pole depth in the middle of the poles to reduce the armature reaction (Fig.17). This kind of methods has also been explored for claw pole machine application in stator teeth [5] and in claw poles [6]. The slits have several functions:

1) set obstacles to Eddy current in solid rotor machines;

2) reduce the armature reaction effect by making the flux path longer: the introduced slits lead to a permeability

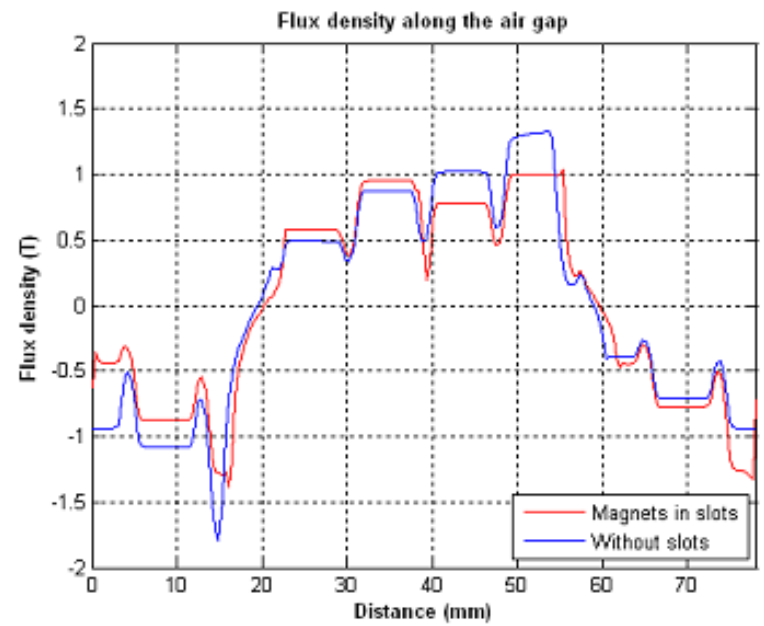

Fig. 18. Comparison of flux density with/without slits 


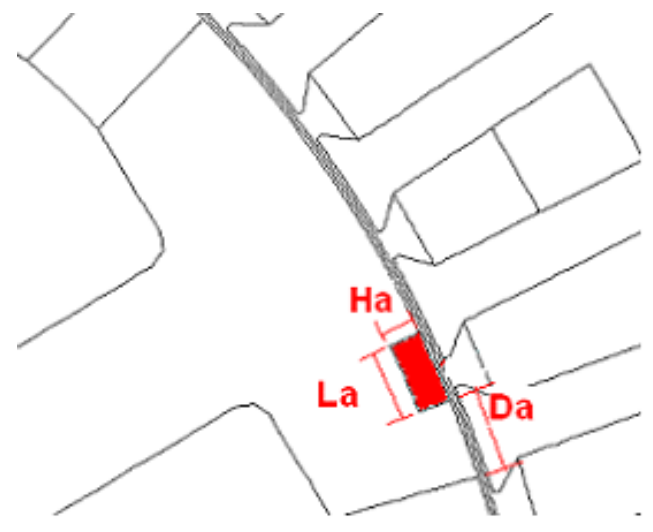

Fig. 19. Parameters for optimization

change and thus the armature reaction has to bypass the slits;

3) provide the possibility to receive eventually a compensating device, like permanent magnets.

The flux density comparison is shown in Fig.18.

\section{NUMERICAL DESIGN OF EXPERIMENTS AND OPTIMIZATION}

The general optimization tool (GOT) which has been developed in Grenoble Electrical Engineering laboratory (G2elab) has been used to optimize the structure, for example, in section III-A the position and the size of the compensating permanent magnets. GOT is a set of tools for the optimization of electromagnetic structures based on intensive numerical calculations which is called 'the sensitivity study'. [8]-[10] The major steps to optimize are:

1) Definition of the optimization problem (uni- or multiobjective);

2) Definition of a 'sensitivity study' according to the parameter sets;

3) Detection of parameter influence, ie. a screening phase to limit the computation time in case of a large number of parameters to deal with;

4) Optimization with deterministic or stochastic algorithms by response surface, ie. to establish the response surface which includes as much information as possible on the structure under study.

In our application, GOT is coupled with the finite elements software FLUX which provides the information necessary for establishing the response surface. The variable parameters are described in Tab.III and Fig.19. The torque is less sensitive to the thickness of the magnet which is fixed for economic reason and for simplification.

The parameters in the response surface are represented by their relative normalized values between $[-1,1]$. A logarithmic function is used for this normalization. The logarithmic function is represented by $\operatorname{Lin}(\mathrm{X}, \mathrm{a}, \mathrm{b})$ in Eq.1 with $\mathrm{a}, \mathrm{b}$ for limit values.

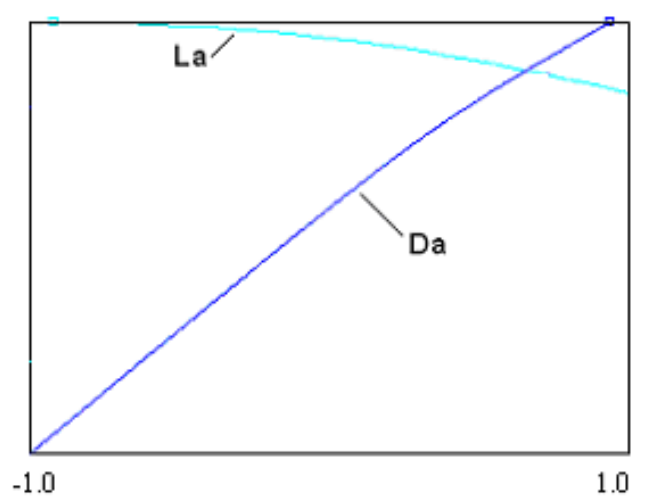

Fig. 20. Response surface around the optimum point

The trend of response surface around the optimum point is shown in Fig.20. The dimensions of the magnets after optimization are given in Tab.IV.

The optimization can be realized for only one operating point according to design needs. The process can be extended to the optimization of the entire machine. In that case, more variables and conditions will be concerned.

$$
\begin{aligned}
\Gamma= & 157.36+3.02 \cdot \operatorname{Lin}(\operatorname{Da}, 2,6) \\
& -0.33 \cdot \operatorname{Lin}(\operatorname{Da}, 2,6) \cdot \operatorname{Lin}(\operatorname{La}, 1,6) \\
& -0.3 \cdot \operatorname{Lin}(\operatorname{La}, 1,6)^{2} \\
& -0.22 \cdot \operatorname{Lin}(\operatorname{La}, 1,6) \\
& -0.18 \cdot \operatorname{Lin}(\operatorname{Da}, 2,6)^{2}
\end{aligned}
$$

\section{CONCLUSION}

Three principal methods based on the principle of armature reaction compensation are presented in the previous sections, which prove to be efficient to improve the characteristics of the present machine at the base speed.

The principal advantage of using permanent magnets is to save additional conductors and current control. Besides, the machine with compensating magnets generates a higher torque

TABLE III

PARAMETERS FOR OPTIMIZATION

\begin{tabular}{|c|l|c|c|}
\hline Parameter & Description & Minimum & Maximum \\
\hline \hline La $(\mathrm{mm})$ & Length of magnet & 1 & 6 \\
\hline $\mathrm{Ha}(\mathrm{mm})$ & Thickness of magnet & \multicolumn{2}{|c|}{ fixed } \\
\hline $\mathrm{Da}(\mathrm{mm})$ & $\begin{array}{l}\text { Distabce between in- } \\
\text { terpolar magnet and } \\
\text { compensating magnet }\end{array}$ & 2 & 6 \\
\hline
\end{tabular}

TABLE IV

OPTIMIZED DIMENSION OF THE COMPENSATING MAGNETS

\begin{tabular}{|c|c|}
\hline Parameter & Value after optimization \\
\hline \hline $\mathrm{La}(\mathrm{mm})$ & 4.4 \\
\hline $\mathrm{Ha}(\mathrm{mm})$ & 2 \\
\hline $\mathrm{Da}(\mathrm{mm})$ & 5.3 \\
\hline
\end{tabular}


than its counterpart when the armature current reaches certain level, ie. when the armature reaction begins to be important.

Secondly, with a progressive air gap, we have obtained a flux density curve smoother with weaker harmonic rate, which helps to reduce the iron losses.

The third method provides the possibility to compensate the armature reaction by the slits in the middle of the poles coupled with magnets.

Nevertheless, these methods can be combined, which needs further study.

An optimization tool (GOT) based on 'sensitivity study' is used to maximize the effect of the three methods presented previously. GOT can also be used to optimize the entire machine.

\section{REFERENCES}

[1] Y. Amara, L. Vido, M. Gabsi, E. Hoang, M. Lécruvain and F. Chabot, Hybrid Excitation Synchronous Machines: Energy Efficient Solution for Vehicle Propulsion, IEEE Conf. Vehicle Power and Propulsion, Windsor, UK, Sep.6-8, 2006.

[2] C. H.Zhao, Y. G.Yan, A Review of Development of Hybrid Excitation Synchronous Machine, IEEE Int. Symposium Industrial Electronics, Dubrovnik, Croatia, Jun. 20-23, 2005.
[3] T. A.Lipo, AC Machine Optimized for Converter Operation, U.S. Patent No. 4573003, Feb.25, 1986.

[4] A. Lacaze, Method and Device for Compensating the Armature Reaction of a Rotating Exciter, U.S. Patent No. 7119472B2, Oct.10, 2006.

[5] L. Bouarroudj, Contribution l'Etude de l'Alternateur Griffes: Application au domaine automobile (Study of Claw Pole Generator for Vehicle Application), Ph.D. dissertation, Grenoble Electrical Engineering Laboratory, INPG France, 2005.

[6] Y. Tamto, Détermination des Paramètres de la Machines Griffes: Application au domaine automobile (Determination of Claw Pole Generator Parameters: For Vehicle Application), Ph.D. dissertation, Grenoble Electrical Engineering Laboratory, INPG France, 2008.

[7] P. Upadhyay, Effect of Armature Reaction and Skewing on the Performance of Radial-flux Permanent Magnet Brushless DC Motor, IEEE Int. Conf. Power Electronics, Drives and Energy Systems, Dec. 12-15, 2006, IIT Delhi, India

[8] J. L.Coulomb, Optimisation, Electromagnétisme et Problèmes Couplés; Electromagnétisme et Eléments Finis 3 (Opitimization, Electromagnetism and Coupled Problems; Electromagnetism and Finite Elements 3), EGEM, Hermes, Jun. 2002

[9] M. C.Costa, J. L.Coulomb, Y. Maréchal, S. I.Nabeta An Adaptive Method Applied to the Diffuse Element Approximation in Optimization Process, IEEE Magnetics, vol.37, no.5, Sep. 2001, pp.3418-3422

[10] M. C.Costa, J. L.Coulomb, Y. Maréchal, S. I.Nabeta Diffuse-Element Method and Quadrees: Two 'Ingredients' for An Adaptive Response Surface, IEEE Magnetics, vol.38, no.2, Mar. 2002, pp.1085-1088 